\title{
Uso de membrana biossintética a base de celulose na regeneração tecidual guiada
}

\author{
Use of biosynthetic cellulose membrane in the guided tissue \\ regeneration
}

\author{
Luciana Santini Iamaguti ${ }^{*}$; Cláudia Valéria Seullner Brandão²
}

\section{Resumo}

\begin{abstract}
A Regeneração Tecidual Guiada (RTG) consiste numa modalidade de tratamento regenerativo que requer a colocação de uma barreira física sobre o defeito ósseo, de modo que a proliferação de tecidos moles adjacentes para dentro da área protegida seja evitada. Assim, a regeneração óssea guiada permite que células com potencial osteogênico das margens ósseas existentes invadam o espaço criado e produzam osso. As barreiras físicas devem ser biocompatíveis, permitir a oclusão celular, manutenção do espaço, integração tecidual e facilidade de uso. Podem ser oclusivas ou permeáveis, absorvíveis ou nãoabsorvíveis. Dentre os vários tipos de barreiras físicas existentes no mercado, a membrana biossintética a base de celulose vem se destacando, pois, além de possuir as características necessárias para a RTG, trata-se de um produto nacional desenvolvido a baixos custos.
\end{abstract}

Palavras-chave: Regeneração tecidual guiada, cartilagem articular, membrana de celulose

\begin{abstract}
Guided Tissue Regeneration (GTR) is a regenerative treatment modality that requires the placement of a physical barrier over a bone defect in such a way that the proliferation of the surrounding soft tissues into the barrier-protected area is prevented. Thereby in the guided osseous regeneration allowing boneforming cells from the existent bone edges to invade the space and produce bone. The physical barriers should be biocompatible, allow cellular occlusion, maintain adequate space, tissue integration and facility in the application. They can be occlusive or permeable, absorbable or non-absorbable. Among various types of physical barriers in the market, the cellulose biosynthetic membrane is emphasizing by the necessary characteristics for GTR and to be a national product developed in low cost.
\end{abstract}

Key words: Guided tissue regeneration, articular cartilage, cellulose membrane

\footnotetext{
1 Mestranda em Cirurgia Veterinária do Departamento de Cirurgia e Anestesiologia Veterinária da FMVZ - Unesp, Botucatu. Botucatu-SP. E-mail: iamaguti_lu@hotmail.com.

2 Professora Assistente Doutora do Departamento de Cirurgia e Anestesiologia Veterinária da FMVZ - Unesp, Botucatu

* Autor para correspondência
} 


\section{Introdução}

A engenharia tecidual consiste em técnica biomédica recente que envolve a manipulação de células para promoção da regeneração de tecidos e substituição de órgãos (TABATA, 2001). A derme, epiderme (FREED; VUNJAK-NOVAKOVIC, 2000), cartilagem articular (SVENSSON et al., 2005), tecido ósseo (REN et al., 2005), tecido epitelial da bexiga (RODRIGUES et al., 2005) e do esôfago (MARZARO et al., 2006) já foram reconstruídos in vitro com sucesso. Contudo, são necessárias condições apropriadas para estimular a organização celular. Assim, as células criam espontaneamente o tecido correspondente enquanto preparam o ambiente ao seu redor via produção de matriz extracelular (FREED; VUNJAK-NOVAKOVIC, 2000).

A regeneração tecidual in vivo utiliza o processo de cicatrização natural do organismo, proporcionando um resultado mais próximo ao real e clinicamente mais aceitável que a regeneração in vitro (TABATA, 2000). Porém, para esse tipo de regeneração, uma barreira física é essencial. Afinal, quando ocorre lesão tecidual, a área ao redor é gradualmente preenchida por tecido fibroso, impossibilitando o reparo por tecido original. Dessa forma, ao se inserir uma membrana junto à lesão, previne-se o crescimento de tecidos indesejáveis (TABATA, 2001).

O uso de membrana separando compartimentos teciduais pode ser considerado uma variação do princípio da Regeneração Tecidual Guiada (RTG), que foi desenvolvida nos anos 60 (BASSET, 1966; RUEDI; BASSET, 1967; NYMAN, 1991; SCHENK et al., 1994). Este princípio foi implantado primeiramente em ortopedia (BASSET, 1966; RUEDI; BASSET, 1967) e, após modificações apropriadas, em odontologia (NYMAN, 1991; BAYLINK; FINKELMAN; MOHAN, 1993; SCHENK et al., 1994), com o intuito de promover o crescimento do osso maxilar e mandibular, além do tecidual.

O estabelecimento dos princípios biológicos da RTG tem orientado pesquisas de vários materiais para desenvolvimento de barreiras físicas que induzirão a formação dos tecidos desejados (MACEDO et al., 2004). A membrana biossintética a base de celulose vem sendo amplamente estudada, pois, além de possuir características necessárias para a RTG (biocompatível, inerte, atóxica, estrutura e resistência adequadas), trata-se de um produto nacional desenvolvido a baixos custos (NOVAES JÚNIOR et al., 1993).

Alguns estudos vêm sendo desenvolvidos para verificar se no tecido cartilaginoso articular, a colocação de membrana de celulose também favoreceria a migração de células com potencial condrogênico, assim como ocorre no tecido ósseo (SVENSSON et al., 2005). Afinal, lesões na cartilagem articular constituem um desafio para a engenharia tecidual, pois este tecido possui capacidade limitada de reparação e as opções de tratamento ainda não apresentaram resultados satisfatórios (LU et al., 2001). O objetivo da presente revisão é apresentar os avanços relacionados à regeneração tecidual guiada com o uso da membrana de celulose, destacando aspectos ósseos e cartilaginosos.

\section{Revisão}

A possibilidade de recuperação do tecido perdido em periodontites ou traumas é demonstrada em vários estudos (NOVAES JÚNIOR; MORAES; NOVAES, 1990; GOTTLOW; KARRING; NYMAN, 1990; LIMA; PASSERI, 1991; NOVAES JÚNIOR; NOVAES, 1993; LANG; BECKER; KARRING, 1997; KARRING; CORTELLINI, 1999; CARVALHO et al, 2003; FUGAZZOTTO, 2003a; FUGAZZOTTO, 2003b; LU, 2003; MACEDO et al., 2003). Em 1976, Melcher (1976)sugeriu que a cicatrização do periodonto era determinada pelo tipo celular que repopulava a superfície da ferida. Este conceito de seleção de população celular influenciou Nyman et al. (1982a) a usar barreiras oclusivas em estudos de regeneração periodontal, que formaram as bases para uma técnica depois conhecida como Regeneração Tecidual Guiada (RTG), ou regeneração tecidual controlada, ou repovoamento celular seletivo, ou cicatrização dirigida. 
Dessa forma, o conceito biológico da RTG baseiase na observação de que a cicatrização desejada pode ser alcançada pela criação de espaço segregado que será povoado pelo tipo celular capaz de regenerar o tecido perdido, como, por exemplo, tecido ósseo, periodontal, etc. (GOTTLOW et al., 1984; GOTTLOW; KARRING; NYMAN, 1990; KARRING et al., 1993; MAJZOUB et al., 1999; CAVALHO et al, 2003; ASLAN; SIMSEK; DAYI, 2004).

Muitas pesquisas e relatos de casos descrevem o uso da RTG no tratamento da atrofia localizada na margem alveolar após extração, prevenindo deformidades ósseas (NOVAES JÚNIOR, 2002), no tratamento de defeitos ósseos associados a implantes osteointegrados (LU, 2003; LANG; BECKER; KARRING, 1997), e em vários tipos de defeitos ósseos como conseqüência de doença periodontal, lesões endodônticas, cistos, traumas (KARRING; CORTELLINI, 1999; WALTERS et al., 2003; SCULEAN; WINDISCH; CHIANTELLA, 2004) e tumores (PELED; MACHTEI; RACHMIEL, 2002).

O tratamento utilizando a RTG envolve a colocação de barreira celular oclusiva sobre o defeito ósseo, de modo que a proliferação de tecidos moles adjacentes para dentro da área protegida seja evitada. Assim, permite-se que células com potencial osteogênico das margens ósseas existentes invadam o espaço criado e produzam osso (NYMAN et al, 1982b; LANG; BECKER; KARRING, 1997; CARVALHO et al., 2003; WIKESJÖ et al., 2003; ASLAN; SIMSEK; DAYL, 2004).

As barreiras físicas facilitam a fixação celular e promovem a migração de células progenitoras. Estas células precisam se aderir a um substrato antes de iniciar a cascata de cicatrização, que consiste na proliferação, diferenciação e maturação tecidual (BURRIDGE, 1986). Esse processo de fixação envolve sequiência de quatro níveis que inclui absorção de glicoproteínas para a superfície do substrato, contato celular, fixação e expansão (BURRIDGE; MOLONY; KELLY, 1987). A replicação celular somente inicia depois que estes eventos tenham ocorrido (SALONEN; PERSSON, 1990).
Há vários fatores a se considerar a respeito do material e estrutura das membranas que serão usadas na RTG. Além de ser biocompatível, ela deve ter a capacidade de criar e manter espaço adequado para suportar o tecido neoformado (OH, et al., 2003). O selamento periférico entre a barreira e a superfície óssea adjacente à área testada deve prevenir o crescimento de tecido conjuntivo externo e o deslocamento da membrana (ASLAN; SIMSEK; DAYL, 2004). Outro fator de importância é o grau de porosidade da barreira que irá influenciar o resultado da cicatrização (LUNDGREN; LUNDGREN; TAYLOR, 1998), bem como se a membrana é absorvível (LU, 2003) ou não-absorvível (MACEDO et al., 2003), e possui facilidade de aplicação.

Quanto à porosidade, as barreiras podem apresentar perfurações com a intenção de otimizar as condições para formação óssea (WIKESJÖ et al., 2003). Contudo, existem controvérsias entre os autores. Lundgren, Lundgren e Taylor (1998) concluíram que membranas sem perfurações ou porosidades (oclusivas) permitiram aumento do tecido ósseo com altura uniforme, superfície nivelada e sem crescimento de tecido conjuntivo. Já as perfuradas (permeáveis), mostraram uma taxa de crescimento ósseo mais eficiente, porém com distribuição desigual e invasão de tecido conjuntivo, independente do diâmetro das perfurações. Mardas et al. (2003) constataram que nas membranas oclusivas, somente células derivadas da cavidade medular, endósteo, endotélio e tecido perivasculares do osso da mandíbula participaram do processo de indução óssea. Já no grupo das membranas permeáveis, foi sugerida pela histologia a migração de células mesenquimais indiferenciadas do tecido conjuntivo subcutâneo e músculos, além da proliferação de tecidos moles adjacentes através das perfurações. Apesar disso, quantidades similares de osso foram formadas nos dois grupos (permeável e oclusiva) independente da falta de migração de células mesenquimais indiferenciadas dos tecidos moles adjacentes. Durante a evolução dos mamíferos, um número reduzido de células pluripotencias se mantém, mas 
diminuem com o passar do tempo (CARPLAN, 1987). Macedo et al. (2003) concluíram que a porosidade da barreira física não foi absolutamente necessária para a neoformação óssea na técnica de RTG; a quantidade de osso formado depende do volume do espaço criado pela membrana.

Com relação às características de absorção dos diferentes tipos de barreiras físicas, ou seja, membrana não-absorvível e absorvível, a primeira membrana não-absorvível comercial aprovada para uso clínico era feita de poli-tetrafluoroetileno expandido (e-PTFE), membrana porosa de teflon (SIGURDSSON et al., 1994; SIMION et al., 1999; SCHOU et al., 2003). Outras membranas nãoabsorvíveis também foram estudadas, como membranas de poli-tetrafluoroetileno (PTFE) (WALTERS et al., 2003), silicone (Biobrane $\left.{ }^{\circledR}\right)$ (WARRER; KARRING, 1992) e celulose (NOVAES JÚNIOR. et al, 1993). Estudos indicam um melhor preenchimento dos defeitos obtidos com o uso de uma membrana não-absorvível (WALTERS et al., 2003). Contudo, este tipo de membrana apresenta algumas desvantagens como: necessidade de segunda intervenção cirúrgica para remoção e elevada taxa de exposição da membrana devido recessão gengival, desconforto para o paciente, elevado custo e infecções pós-operatórias (SIMION et al., 1999).

Membranas absorvíveis com características similares às não-absorvíveis foram então desenvolvidas: membranas de colágeno $(\mathrm{OH}$ et al., 2003; STAVROPOULOS et al, 2004), ácido poliláctico (Guidor®) (CURY et al., 2005), poliglactina 910 (Vicryl®) (LU, 2003) e ácido poliláctico glicólico (PLGA®) (SONG et al., 2005). Elas são conhecidas clinicamente, sobretudo devido ao fato de que uma segunda intervenção cirúrgica seja desnecessária, pois se espera que sejam completamente reabsorvidas em 12 meses (GOTTLOW et al., 1994). Entretanto, Cury et al. (2005) encontraram resíduos da membrana absorvível de ácido poliláctico em um paciente após dois anos, proporcionando um efeito estimulante ou irritante nas células inflamatórias. Apesar disso, elas apresentam melhor manuseio e adaptação ao redor do dente e sobre o osso, boa integração aos retalhos de tecido conjuntivo com a membrana, prevenindo a migração de tecido epitelial, recessão gengival e manutenção de um espaço entre a membrana e o retalho. Essas vantagens promovem conforto para o paciente, redução do tempo de tratamento, minimização das complicações pós-operatórias, melhorando os resultados (PARASHIS et al., 1998). Contudo, Fugazzotto (2003a) e Fugazzotto (2003b) constatou que quando não fixadas, as membranas absorvíveis permitem movimentos e reabsorção que provocam o rompimento na superfície do coágulo, levando ao desenvolvimento de tecido mole entre a membrana e o coágulo rompido, diminuindo a quantidade de reparação óssea.

No caso de aplicações em cavidade oral, cuidados devem ser tomados com relação a anti-sepsia pósoperatória para que não ocorra contaminação e perda da mesma Fugazzotto (2003a) e Fugazzotto (2003b).

A membrana de celulose, sintetizada pela bactéria Acetobacter xylinum, é estudada desde os anos 60 (WEBB; COLVIN, 1967). Na década de 80, o LQBB - Laboratório de Quimio/Biotecnologia de Biomassa da Universidade Federal do Paraná desenvolveu uma película de celulose pura microfibrilar biossintética, obtida por um processo de fermentação desta bactéria. Atualmente, a membrana vem sendo utilizada como substituto da pele (REBELLO et al., 2001), curativo de feridas cirúrgicas de papilas mamárias de vacas (Biofill@) (MARQUES et al., 1991), curativo para cirurgias periodontais (Gengiflex $\left.{ }^{\circledR}\right)$ (NOVAES JÚNIOR. et al., 1993), reconstrução vascular (KLEMM et al., 2001), substituto da dura-máter (MELLO et al., 1996), entre outras aplicações em estudo. Essa membrana é constituída por uma camada formada por rede de microfibrilas de celulose cristalina prensadas que dão estrutura e rigidez à membrana. A do tipo Gengiflex® possui também uma camada externa de alcalicelulose que é, na realidade, uma modificação química da camada interna. Este processo biotecnológico de baixo custo permite à membrana de celulose um 
preço mais acessível (NOVAES JÚNIOR. et al., 1993). O produto possui características biocompatíveis, sendo biodegradável (SALATA et al., 2001), inerte, atóxico e seletivamente permeável (NOVAES JÚNIOR; NOVAES, 1993), possuindo as qualidades necessárias para a RTG.

Novaes Júnior, Moraes e Novaes (1990), descreveram uma técnica cirúrgica utilizando Biofill@, no tratamento de lesão de furca em odontologia, sendo que os resultados apresentados revelavam sucesso na sua utilização. Com o propósito de minimizar algumas dificuldades inerentes do procedimento de enxerto gengival livre, Lima e Passeri (1991) utilizaram uma película microfibrilar tipo celulósica. Após controle da hemorragia, várias camadas de película sintética foram colocadas no intuito de revestir o leito receptor, sendo mantida em posição pelo coágulo sanguiíneo. Após avaliação clínica, apesar da pequena amostra (cinco pacientes), os autores concluíram, ao final dos períodos de 15 e 30 dias, que a película sintética permitiu a substituição da camada superficial, sem interferir com a reparação do leito receptor.

Há uma preocupação do cirurgião quanto à perda óssea ocorrida nos diversos procedimentos cirúrgicos, assim como a formação de tecido fibroso onde deveria existir tecido ósseo, limitando a perfeita adaptação de próteses futuramente. Por isto muitas pesquisas têm sido realizadas no sentido de possibilitar a aplicação de materiais no interior de cavidades ósseas, nas quais possam vir a ocorrer uma loja óssea após o procedimento cirúrgico (NOVAES JÚNIOR. et al., 1993). Na tentativa de reconstrução total ou parcial dessas estruturas perdidas, desenvolveramse técnicas com o objetivo de recuperar o contorno anatômico normal, eliminar espaços mortos, favorecer a cicatrização, além de prevenir a invaginação de tecidos moles para o interior dessas cavidades, reduzindo assim as chances de infecções secundárias (NOVAES JÚNIOR. et al., 2002). Novaes Júnior e Novaes (1993) descreveram restauração completa de defeito ósseo ao redor de implante de titânio. A GengiflexÒ foi usada na RTG para cobrir o implante e a hidroxiapatita foi utilizada como material de enxerto. O preenchimento do defeito foi verificado clinicamente após seis meses e a análise histológica durante a exposição do implante confirmou a formação óssea. Estudos estão sendo realizados na busca por materiais que substituam o osso perdido, ou ainda técnicas que venham a possibilitar a formação do osso a partir de um substrato ósseo preexistente (como o uso de membranas), ou ainda de substâncias que induzam a formação óssea (NOVAES JÚNIOR; NOVAES, 1993; NOVAES JÚNIOR. et al., 2002; MACEDO et al, 2004).

A membrana de celulose também foi empregada como substituto de dura-máter em cães e apresentou pouca reação fibrótica (MELLO et al., 1996), sendo considerada, portanto, material adequado para enxerto dural. A análise destas características histológicas sugere que a celulose sofre degradação no organismo animal, por processo bioquímico a esclarecer. $\mathrm{O}$ achado de partículas refringentes de celulose no citoplasma das células gigantes, em ratos que receberam implante de celulose no fígado, sugeriu absorção do material por fagocitose (MELLO et al., 2001).

Em estudo desenvolvido por Salata et al. (2001), foi demonstrado que o modelo de reparação óssea encontrada no grupo da membrana de celulose foi predominantemente de ossificação endocondral. Em contraste, a membrana de e-PTFE induziu formação óssea direta (ossificação intramembranosa). A formação de cartilagem durante a reparação óssea é considerada como consequiência da baixa tensão de oxigênio no tecido. Sandberg, Dahlin e Linde (1993) observaram áreas de cartilagem nos defeitos mandibulares experimentais de ratos revestidos por membrana. A presença de cartilagem pode ter ocorrido devido à baixa tensão de oxigênio gerada pelo selamento do suprimento vascular periosteal. Salata et al. (2001) concluíram que devido à presença de inflamação severa, provavelmente pela biodegradação da membrana, os requisitos para o acúmulo de proteína morfogenética não foram encontrados com o uso da membrana de celulose. 
Todos esses efeitos combinados podem levar a formação de cartilagem, no lugar da deposição óssea direta, nos defeitos cobertos com essa membrana.

Svensson et al. (2005) desenvolveram um estudo para avaliar o potencial da membrana de celulose na reparação da cartilagem in vitro, observando um crescimento significativo de condrócitos viáveis. Os resultados obtidos nesse estudo sugerem a possibilidade de RTG do tecido cartilaginoso, que possui capacidade limitada de reparo após lesão.

\section{Conclusão}

Muitas pesquisas vêm sendo realizadas para desenvolver novos métodos terapêuticos para melhorar a reparação osteocondral. O uso de arcabouços na engenharia tecidual é essencial para suportar a proliferação celular e manter suas funções diferenciadas. A preconização de membranas que possuam a porosidade adequada, ao mesmo tempo em que sejam biocompatíveis e suportem o crescimento tecidual, com taxas de degradação comparadas com as de formação do novo tecido é o fundamento da regeneração tecidual guiada. A membrana biológica biossintética nacional, a base de celulose, vêm se destacando como um produto promissor a ser aplicado na Regeneração Tecidual Guiada não só do tecido osteocartilaginoso como também, de vários outros tecidos.

\section{Referências}

ASLAN, M.; SIMSEK, G.; DAYL, E. Guided bone regeneration (GBR) on healing bone defects: a histological study in rabbits. Journal of Contemporary Dental Practice, Turkey, v.2, n.5, p.114-23, 2004.

BASSET, C. A. Environmental and cellular factors regulating osteogenesis. In: FROST, $\mathrm{H}$. (Ed). Bone Biodynamics. Boston: Little Brown, 1966. p.233-244.

BAYLINK, D. J.; FINKELMAN, R. D.; MOHAN, S. Growth factors to stimulate bone formation. Journal of Bone and Mineral Research, Washington, v.8, supl.2., p.565-572, Dec. 1993.

BURRIDGE, K. Substrate in normal and transformed fibroblast: Organization and regulation of cytoskeletal, membrane and extra cellular matrix components at focal contacts. Cancer: revue bibliographique, Villejuif, v.4, p.18-78, 1986.

BURRIDGE, K.; MOLONY, L.; KELLY, L. Adhesion plaques: sites of transmembrane interaction between the extra cellular matrix and the actin cytoskeleton. Journal of Cell Science, London, v.8, p.211-229, 1987.

CARPLAN, A. I. Bone development and repair. Bioessays, Cambridge, v.6, p.171-175, 1987.

CARVALHO, R. S.; NELSON, D.; KELDERNIAN, H.; WISE, $\underline{\mathrm{R}}$. Guided bone regeneration to repair an osseous defect. American Journal of Orthodontics and Dentofacial Orthopedics, Saint Louis, v.123, n.4, p.455-67, 2003.

CURY, P. R.; FURUSE, C.; MARTINS, M. T.; SALLUM, E. A; ARAUJO, N. S. Root resorption and ankylosis associated with guided tissue regeneration. Journal of the American Dental Association, São Paulo, v.136, n.3, p.337-341, 2005.

FREED, L. E.; VUNJAK-NOVAKOVIC, G. Tissue engineering bioreactors. In: LANGER, R.; VANCANTI, J. P. (Ed.). Principle of Tissue Engineering. Massachusetts: Academic Press, 2000. p.143-156.

FUGAZZOTTO, P. A. GBR using bovine bone matrix and resorbable and non resorbable membranes. International Journal of Periodontics and Restorative Dentistry, Chicago, v.23, n.4, p.361-367, 2003a.

. GBR using bovine bone matrix and resorbable and non resorbable membranes. Part 2: Clinical results. International Journal of Periodontics and Restorative Dentistry, Chicago, v.23, n.6, p.599-605, 2003 b.

GOTTLOW, J.; KARRING, T.; NYMAN, S. Guided tissue regeneration following treatment of "recession type defects" in the monkey. Journal of Periodontology, Chicago, v.61, n.11, p.680-685, 1990.

GOTTLOW, J.; LAURELL, L.; LUNDGREN, D. MATHISEN, T.; NYMAN, S.; RYLANDER, H. Periodontal tissue response to a new bioresorbable guided tissue regeneration device: a longitudinal study in monkeys. International Journal of Periodontics and Restorative Dentistry, Chicago, v.14, p.436-449, 1994.

GOTTLOW, J.; NYMAN, S.; KARRING, T.; LINDHE, J. New attachment formation as the result of controlled tissue regeneration. Journal of Clinical Periodontology, Copenhagen, v.11, n.8, p.494-503, 1984.

KARRING, T.; CORTELLINI, P. Regenerative therapy: furcation defects. Periodontology 2000, Copenhagen, v.19, p.115-137, 1999.

KARRING, T.; NYMAN, S.; GOTTLOW, J.; LAURELL, L. Development of the biological concept of guided tissue regeneration: animal and human studies. Periodontology 2000, Copenhagen, v.1, p.26-35, 1993. 
KLEMM, D.; SCHUMANN, D.; UDHARDT, U.; et al. Bacterial synthesed cellulose-artificial blood vessels for microsurgery. Progress in Polymer Science, Elmsford, v.26., p.1561-1603, 2001.

LANG, N. P.; BECKER, W.; KARRING, T. Alveolar bone formation. In: LINDHE, J.; KARRING, T.; LANG, N. P. (Ed.). Clinical Periodontology \& Implant Dentistry. 3.ed. Demark: Munksgaard, 1997. p.906-937.

LIMA, A. F. M.; PASSERI, L. A. Enxerto gengival : procedimento alternativo. Revista Paulista de Odontologia, São Paulo, v.13, n.4, p.25-7, 1991.

LU,L.;ZHU, X.; VALENZUELA, R. G.; et al. Biodegradable polymer scaffolds for cartilage tissue engineering. Clinical Orthopaedics and Related Researsch, Philadelphia, n.391S, p.S251-S270, 2001.

LU, S. Guided bone regeneration using an absorbable membrane combined with a one-stage implant into a recent extraction site: a case report. Quintessence International, Berlin, v.34, p.253-7, 2003.

LUNDGREN, A.; LUNDGREN, D.; TAYLOR, A. Influence of barrier occlusiveness on guided bone augmentation: an experimental study in the rat. Clinical Oral Implants Research, Copenhagen, v.9, n.4, p.251-60, 1998.

MACEDO, N. L.; MATUDA, F. S.; DE MACEDO, L. G. S.; MONTEIRO, A. S. F.; VALERA, M. C.; CARVALHO, Y.R. Evaluation of two membranes in guided bone tissue regeneration: histological study in rabbits. Brazilian Journal of Oral Science, Piracicaba., v.3, n.8, p. 395-400, 2004.

MACEDO, N. L.; MACEDO, L. G. S.; MATUDA, F. S;. MONTEIRO, A. S. F.; CARVALHO, Y. R. Guided bone regeneration with subperiosteal implants of PTFE and hydroxyapatite physical barriers in rats. Brazilian Dental Journal, Ribeirão Preto, v.14, n.2, p.119-24, 2003.

MAJZOUB, Z.; BERENGO, M.; GIARDINO, R.; ALDINI; N. N.; CORDIOLI, G. Role of intra marrow penetration in osseous repair: a pillot study in the rabbit calvaria. Journal of Periodontology, Chicago, v.70, n.12, p.1501-10, 1999.

MARDAS, N.; KOSTOPOULOS, L.; STAVROPOULOS, A.; KARRING, T. Evaluation of a cell-permeable barrier for guided tissue regeneration combined with demineralized bone matrix. Clinical Oral Implants Research, Copenhagen, v.14, n.6, p. 812-8, 2003.

MARQUES, J. A.; DALECK, C. R.; MARQUES, L. C.; GOMES, M. C. Curativo biológico (Biofill) no tratamento de feridas cutâneas de papilas mamárias de vacas. A Hora Veterinária, Porto Alegre, v.11, n.61, p.39-42, 1991.

MARZARO, M.; VIGOLO, S.; OSELLADORE, B., CONCONI, M. T. In vitro and in vivo proposal of an artificial esophagus. Journal of Biomedical Materials Researsh Part A, Hoboken, v.77, n.4, p.795-801, 2006.
MELCHER, A.H. On the repair of the periodontal tissues. Journal of Periodontology, Chicago, v.47, p.256-60, 1976.

MELLO, L. R.; FELTRIN, Y.; SELBACH, R.; MACEDO Jr., G.; SPAUTZ, C.; HAAS, L. J. Uso da celulose liofilizada em lesões de nervos periféricos com perda de substância. Arquivo Neuro-Psiquiatria, São Paulo, v.59, n.2B, 2001.

MELLO, L. R.; FELTRIN, L. T.; FONTES NETO, P. T. L.; ABREU, A. R. Duraplastia com celulose biossintética estudo experimental. Arquivo Brasileiro de Neurocirurgia, São Paulo, v.15, p.14-21, 1996.

NOVAES JUNIOR., A. B.; MORAES, N.; NOVAES, A.B. Uso do BioFill como membrana biológica no tratamento de lesão de furca com e sem a utilização de hydroxiapatita porosa. Revista Brasileira Odontologi, Rio de Janeiro, v.46, p.29-33, 1990.

NOVAES JUNIOR., A. B.; NOVAES, A. B.; GRISI, M. F. M.; SOARES, U. N.; GABARRA, F. Gengiflex, an alkalicellulose membrane for GTR: histologic observations. Brazilian Dental Journal, Ribeirão Preto, v.4, n.2, p.6571, 1993.

NOVAES JUNIOR., A. B.; PAPALEXIOU, V.; LUCZYSZYN, S. M.; MUGLIA, V.; SOUZA, S. L. S.; TABA, M. Immediate implant in extraction socket with acellular dermal matrix graft and bioactive glass: a case report. Implant Dentistry, Baltimore, v.11, n.4, p.343-8, 2002.

NOVAES JUNIOR., A. B.; NOVAES, A. B. Bone formation over a $\mathrm{TiAl}_{6} \mathrm{~V}_{4}$ (IMZ) implant placed into an extraction socket in association with membrane therapy (Gengiflex). Clinical Oral Implant Research, Rio de Janeiro, v. 4, p. 106-10, 1993.

NYMAN, S. Bone regeneration using the principle of guided tissue regeneration. . Journal Clinical Periodontology, Copenhagen, v.18, p.494-8, 1991.

NYMAN, S.; GOTTLOW, J.; KARRING, T.; LINDHE, J. The regenerative potential of the periodontal ligament. An experimental study in monkey. Journal of Periodontology, Chicago, v.9, p.257-65, 1982a.

NYMAN, S.; LINDHE, J.; KARRING, T.; LANDER, H. R. New attachment following surgical treatment of human periodontal disease. Journal of Clinical Periodontology, Copenhagen, v.9, p.290-6, 1982b.

OH, T.; MERAW, S. J.; LEE, E.; GIANNOBILE, W. V.; WANG, H. L. Comparative analyses of implant dehiscence defects. Clinical Oral Implant Research, Copenhagen, v.14, n.1, p.80-90, 2003.

PARASHIS, A.; ANDRONIKAKI-FALDAMI, A.; TSIKLAKIS, K.; VAN DER STELT, P. F. Clinical application of a new bioresorbable guided tissue regeneration device: case reports. International Journal of Periodontics and Restorative Dentistry, Chicago, v.18, n.4, p.389-401, 1998. 
PELED, M.; MACHTEI, E. E.; RACHMIEL, A. Osseous reconstruction using a membrane barrier following marginal mandibulectomy: an animal pilot study. Journal of Periodontology, Chicago, v.73, p.1451-6, 2002.

Placed into an extraction socket in association with membrane therapy (Gengiflex). Clinical Oral Implants Research, Copenhagen, v.4, p.106-10, 1993.

REBELLO, C.; ALMEIDA, D. A.; LIMA JUNIOR., E. M.; DORNELAS, M. P. Biofill, um novo substituto de pele: nossa experiência. Revista Brasileira de Cirurgia, São Paulo, v.26, p.1561-1603, 2001.

REN, T.; REN, J.; JIA, X.; PAN, K. The bone formation in vitro and mandibular defect repair using PLGA porous scaffolds. Clinical Oral Implants Research, Copenhagen, v.74, n.4, p.562-9, 2005.

RODRÍGUEZ, E. D.; EDREIRA, A. R., PEÑA, A. V.; INFIESTA, A. M.; LLAMES, S. G.; GARCÍA, B. M.; ORTEGA, J. M. G. In vitro three-dimensional reconstruction of human bladder mucosa. Actas Urológicas Españolas, Madrid, v.30, n.2, p.195-205, 2005.

RUEDI, T. P.; BASSET, C. A. Repair and remodeling in Millipore-isolated defects in cortical bone. Acta Anatomica, Basel, v.68, p.509-31, 1967.

SALATA, L. A.; HATTON, P. V.; DEVLIN, A. J.; BROOK, I. M.; CRAIG, G. In vitro and in vivo evaluation of e-PTFE and alkali-cellulose membranes for guided bone regeneration. Clinical Oral Implants Research, Copenhagen, v.12, n.1, p.62-8, 2001.

SALONEN, J. I.; PERSSON, R. G. Migration of epithelial cell on material used in guided tissue regeneration. Journal Periodontal Research, Copenhagen, n.25, p.215-21, 1990.

SANDBERG, D.; DAHLIN, C.; LINDE, A. Bone regeneration by the osteopromotion technique using bioabsorbable membranes: an experimental study in rats. Journal of Oral Maxillofacial Surgery, Philadelphya, v.51, n.10, p.1106-14, 1993.

SCHENK, R. K.; BUSER, D.; HARDWICK, W. R.; DAHLIN, C. Healing pattern of bone regeneration in membraneprotect defects: A histologic study in the canine mandible. International Journal of Oral Maxilofacial Implants, Carol Strean, v.9, p.13-29, 1994.

SCHOU, S.; HOLMSTRUP, P.; JORGESNSE, T.; SKOVGAARD, L. T.; STOLTZE, K.; HJORTING-HANSEN, E.; WENZEL, A. Anorganic porous bovine-derived bone mineral (Bio-Oss $®$ ) and e-PTFE membrane in the treatment of periimplantis in cynomolgus monkey. Clinical Oral Implants Research, Copenhagen, v.14, n.5, p.535-47, 2003.

SCULEAN, A.; WINDISCH, P.; CHIANTELLA, G. C. Human histologic evaluation of an intrabony defect treated with enamel matrix, derivative xenograft and GTR.
International Journal of Periodontics and Restorative Dentistry, Chicago, v.24, p.326-33, 2004.

SIGURDSSON, T. J.; HARDWICK, R.; BOGLE, G. C. WIKESJÖ U. Periodontal repair in dogs: space provision by reinforced e-PTFE membranes enhances bone and cementum regeneration in large supra-alveolar defects. Journal Periodontology, Chicago, v.65, p.350-6, 1994.

SIMION, M.; DAHLIN, C.; BLAIR, K.; SCHENK, R. Effect of different microstructures of e-PTFE membranes on bone regeneration and soft tissue response: a histologic study in canine mandible. Clinical Oral Implants Research, Copenhagen, v.10, n.2, p.73-84, 1999.

SONG, W. S.; KIM, C. S.; CHOI, S. H.; JHON, G. J.; KIM, H. Y.; CHO, K. S.; KIM, C. K.; CHAI, J. C. The effects of a bioabsorbable barrier membrane containing safflower seed extracts on periodontal healing of 1-wall intrabony defects in beagle dogs. Journal of Periodontology, Chicago, v.76, n.1, p.22-33, 2005.

STAVROPOULOS, F.; DAHLIN, C. L; RUSKIN, J. D.; JOHANSSON, C. A. comparative study of barrier membranes as graft protectors in the treatment of localized bone defects: an experimental study in a canine model. Clinical Oral Implants Research, Copenhagen, v.15, n.4, p.435-42, 2004.

SVENSSON, A.; NICKLASSON, E.; HARRAH, T.; PANILAITIS, B.; KAPLAN, D. L.; BRITTBERG, M.; GATENHOL, M. P. Bacterial cellulose as a potential scaffold for tissue engineering of cartilage. Biomaterials, Surrey, v.26, p.419-31, 2005.

TABATA, Y. Recent progress in tissue engineering. Drug Discovery Today, Kidlington, v.6, n.1, p.483-7, 2001.

The importance of drug delivery systems in tissue engineering. Pharmaceutical Science Technology Today, Kidlington, v.3, p.80-9, 2000.

WALTERS, S. P.; GREENWELL, H.; HILL, M; DRISKO, C.; PICKMAN, K.; SCHEETZ, J. P. Comparison of porous and non-porous Teflon membranes plus a xenograft in the treatment of vertical osseous defects: a clinical reentry study. Journal of Periodontology, Chicago, v.74, p.1161-8, 2003.

WARRER, K.; KARRING, T. Guided tissue regeneration combined with osseous graft in suprabony periodontal lesions. Journal of Clinical Periodontology, Copenhagen, v.19, n.6, p.373-80, 1992.

WEBB, T. E.; COLVIN, J. R. The extracellular proteins of Acetobacter xylinum and their relationship to cellulose synthesis. Can. J. Biochem., Oceanside, v.45, n.4, p.465$76,1967$.

WIKESJÖ, V. M. E.; LIM, W. H.; THOMSON, R. C.; HARDWICK, W. R. Periodontal repair in dogs: gingival tissue occlusion, a critical requirement for GTR? Journal of Clinical Periodontology, Copenhagen, v.30, n.7, p. 